\title{
Caçada de onças. Um relato etnográfico de um filme perdido de Luiz Thomaz Reis*
}

Fernando de Tacca***

\section{Resumo}

Descrição das filmagens e das situações em que Reis esteve envolvido nas preparações da caçada e nos momentos em que esteve frente a alguns felinos. O relato é também uma descrição de valor etnográfico sobre o sertanejo e suas relações com a natureza. Palavras-chave: Serviço de Proteção ao Índio (SPI); cinema; etnografia; Amazônia.

\begin{abstract}
This article describes the filmings and the situation where Reis was envolved when he prepared the hunt and the moments where he was face to some animals. It is also a ethnographic valous description about the "sertanejo" (hinterlander) and his relationships with the nature.
\end{abstract}

Keywords: Serviço de Proteção ao Índio (SPI); movie; ethnography; Amazonian.

O relatório em questão é uma descrição das filmagens e das situações em que Reis esteve envolvido nas preparações da caçada e nos momentos em que esteve frente a alguns felinos, mas o relato é também uma descrição de valor etnográfico sobre o sertanejo e suas relações com a natureza. A caçada de onça coloca o homem frente à natureza selvagem e ao enfrentar o felino somente com armas brancas cria uma situação de "igualdade" de chances, mas a espera e o controle das marcas indiciais deixadas no chão e outros indícios colocam a peleja no campo da estratégia, no descobrimento dos passos do inimigo. Existem muitas histórias sobre os felinos

\footnotetext{
* Documento microfilmado MI SARQ Microfilme 328, fotogramas 1090 a 1131. Agradeço a Denise Portugal Lasmar a apresentação do relatório. Sua pesquisa resultou na dissertação de mestrado "Estoques de informação: o acervo imagético da Comissão Rondon no Museu do Índio como fonte de informação", no Programa de Pós-Graduação em Ciência da Informação da Escola de Comunicação da UFRJ.

** Fotógrafo, doutor em Antropologia Social (USP), Professor Livre Docente no Departamento de Multimeios, Mídia e Comunicação, IA/Unicamp. Professor Visitante na Universidade de Estudos Estrangeiros de Osaka, Japão (1995-97). Assumiu a Cátedra de Estudos Brasileiros na Universidade de Buenos Aires, em 2004. Recebeu o Prêmio Pierre Verger de Ensaio Fotográfico - 2006, da Associação Brasileira de Antropologia, e o Prêmio de Reconhecimento Acadêmico Zeferino Vaz, Unicamp, 2006. Atualmente é coordenador do Núcleo de Pesquisa "Fotografia: Cultura e Comunicação", da INTERCOM, e editor da Revista Eletrônica Studium: http://www.studium.iar.unicamp.br
} 
Caçada de onças. Um relato etnográfico de um filme...

entre os sertanistas e nos relatos de Rondon, principalmente pelo fato de pouco serem vistos durante o dia e, assim, o imaginário torna-se fecundo em memórias orais. Suas conversas, suas ansiedades e a mentalidade do sertanista são tratadas por Reis. O relato nos conta o cerco a três felinos e como Reis colocou-se a filmar esses eventos.

Reis diz que não pôde tomar cenas de uma caçada quando estava acompanhando Theodor Roosevelt, junto com Rondon (1914), porque o expresidente dos Estados Unidos da América não permitiu ser filmado, não queria ele aparecer em películas caçando onças no Brasil. A idéia, então, de fazer um filme sobre caçadas de onças estava presente desde essa época, poucos anos antes. Depois de muitas consultas em Corumbá, somente um fazendeiro, Leôncio Nery, da fazenda Campoleda, lhe deu apoio e garantias de uma filmagem segura, e com uma luta em que o caçador estivesse com uma arma branca. Leôncio Nery havia sido companheiro seu na Escola Militar da Praia Vermelha.

Antes mesmo da chegada de Reis um grupo de sertanistas já estava à procura de rastros. Entre o grupo de apoio a Reis, estava um indivíduo chamado de "índio Fortunato", que já havia caçado mais de 180 onças, e que afirmava ser muito difícil acuá-las em campo limpo, e sim sempre no cerrado, mas disse que poderia limpar o terreno para as filmagens, sendo muito difícil acompanhar todas as etapas, e principalmente por ser Reis um iniciante teria medo da proximidade com o animal. O grupo caçador de onças e imagens compunha-se dos fazendeiros Leôncio Nery (e seu irmão), Cornélio Rondon, índio Fortunato, dois "camaradas" armados com carabinas Winchester, um foiceiro e dois peões para carregar o equipamento de filmagem.

O primeiro dia de tentativas foi fracassado, com os cães nada percebendo, e sem rastros, somente um antigo, de dois dias anteriores, com pouca clareza pela chuva que apagou parte dos indícios. No segundo dia somente os sertanistas mais experientes saíram para procurar rastros e voltaram com a informação de que um grande animal havia circulado por perto da casa, perto do local onde se lavava a roupa da família. Reis $(1918)^{1}$ descreve a chegada da informação:

A informação agradou a todos, principalmente ao Fortunato, cujas pupillas brilharam; dilatando as azas do nariz e retorcendo os poucos fios de um negro bigode espinhado, sobre uma bocca de linhas regulares e estreitos labios,

38 Somanlu, ano 7, n. especial 2007 

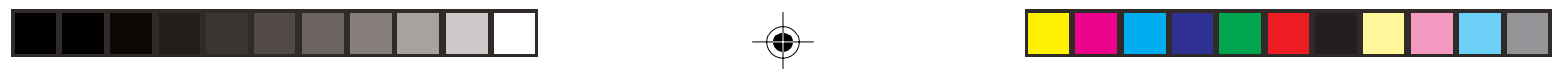

Fernando de Tacca

indicando o sangue frio e o espírito meditativo, elle sorrio apenas, furtivamente, emquanto nós gargalhavamos. $\mathrm{O}$ Cornelio, com uma franqueza e jovialidade natural do seu temperamento, ria-se a todo o instante, dizendo: "Vamos ver como seu tenente vae se arranjar amanhã". Passou-se a noite para mim cheia de sonhos fantásticos; eu não cuidava do custo da empresa, de caçar onça de verdade; mas de poder obter um bom film o que de certo me compensaria de todos os riscos ou desgostos por peiores que fossem. Quando accordei sob os latidos dos cachorros mobilizados para a caça, o quarto estava claro; abri uma janella do meu alojamento, por onde uma onda de sol invadiu o ambiente.

Depois de buscas encontrou rastros mais frescos para os quais Fortunato chama um cachorro com liderança, conhecido mestre-onceiro, que cheira o rastro e parte para banhados e terrenos inacessíveis para os cavalos, em ritmo de idas e vindas, para captar novamente o cheiro do animal na trilha deixada por suas pegadas. Comandando e conduzindo a matilha estava Fortunato.

A primeira fase da caçada havia começado quando se deu o que diziam os sertanistas: "deu no rasto o Teimoso" (nome do cachorro mestre). Essa fase foi de buscas soltas dos cães que se agitavam intermitentemente, mas com objetividade. Aproximou-se o momento de preparar o equipamento na segunda fase da caçada, somente com seus ajudantes,

[... começando por armar a tripede e atarrachar as lentes para o trabalho. Já o Fortunato e o Cornelio tinham desapparecido e commigo estavam apenas os camarradas; não sabiamos por onde começar: na mata um reboliço extranho de galhos quebrados violentamente, lamentações de cães, de mistura com os agudos latidos dos mestres, e a zoada de pesados passos que succediam ao farfalhar de folhas sacudidas, tudo indicava a terrivel perseguição que ia pelos escuros recantos da floresta (1918).

Chegava o momento esperado. Reis e seus ajudantes tiveram que sair carregando os aparelhos já preparados por um caminho que lhes indicavam, e onde também limpavam o terreno para as filmagens. Sobre um tronco estava uma onça parda atenta aos cachorros abaixo, em latidos altos e raivosos. Reis (1918) descreve 
o ambiente com detalhes das cores das folhagens e das luzes do local. Diz ele sobre a filmagem nesse momento:

Estacionei o apparelho numa distancia de uns oito metros apontando-o para o alto. Os cães continuavam a latir acuando do lado opposto ao nosso; assim a onça voltou-se sobre o batovi e deu-nos as costas para espial-os. Comecei a trabalhar fazendo girar a manivella do apparelho onde o film principiou a se deslocar com o instantaneo de 1/250 de segundo; o atirador estava com a arma em ponto esperando só a voz de "fogo" para disparal-a. Era eu que devia dar essa voz no momento por mim julgado opportuno. Em frente ainda restavam alguns arbustos e pequenos acurys mascarando o provavel theatro da lucta quando a onça baixasse "do páo"; mandei pois roçar ainda esse trecho, obtendo com isso um pouco mais de luz, preciosa naquelle momento... Dei a voz de fogo para apenas ferir mal a fera, na esperança de que esta saltasse sobre os zagaieiros, o que seria uma lucta sensacional que me proporcionaria um grande film importante. O Nery, com a Winchester no ponto, alvejou a onça na espinha dorsal, e, emquanto o film corria no chassis, o tiro partiu, echoando estrepitosamente pela mata a dentro; os zagaieiros, de ferro em riste, apontavam para o batovi espera do tigre furioso, cujo rugido pouco e desesperado fôra o prenuncio do ataque. No chão os cães, em conjuncto, saltavam na direcção do tronco, como a quererem attingir a altura onde estava a onça.

Reis esperava que um tiro não mortal fizesse com que a onça saltasse sobre o sertanista, o que propiciaria um filme mais "importante", com uma luta entre homem e animal. Mortalmente ferida, caiu do tronco com os cães sobre ela e os zagaieiros enterraram suas zagaias no peito do felino, mas na luta a onça feriu vários cachorros e foi-lhe dado o tiro mortal. E completa Reis (1918) sua visão de cineasta:

Emquanto os caçadores comentavam os diversos incidentes da aventura, ia eu meditando sobre a quasi impossibilidade de atingir os resultados que eu pensava poder obter, quando pretendi tomar um film desta natureza. Como acabara de apreciar, a opportunidade tinha sido a melhor, bons cães, bons zagaieiros, scenarios um tanto escuros mas de possivel

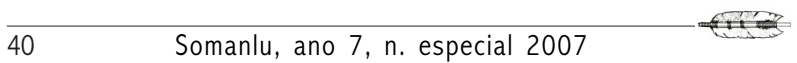


impressão photographica; a onça alli estava, mas já morta, sem mais effeitos de animação que é a vida do film.

Frustrado com a falta de ação e resignado a tomar somente uns "restos de assunto", a onça morta, Reis, insatisfeito ainda, quer continuar as caçadas para completar o filme. Passados alguns dias, segue-se o relato de mais dois cercos em dois felinos e as implicações na filmagem. No segundo cerco, alguns lances foram de tensão e medo, pois a onça esteve muito perto de Reis.

Encontrado um rastro recente, os peões o identificaram com uma grande espécie e fêmea. A descrição da ação dos cães e de sua relação com seus donos é rica e detalhada. Em meio à mata, com enxames de mosquitos, Reis acompanhava a entrada em mato alto, chegando a ficar preso entre cipós, e com receio chamou pelos assistentes para não ser uma presa fácil. Livre dos arbustos, encontra o resto da tropa a observar uma onça também em um tronco alto. Novamente ainda houve tempo para preparar o terreno e limpar ao redor para instalação dos equipamentos:

Desta vez para que o tiro não fosse mortal, mandei o Nery alvejal-a a revolver, numa das patas dianteiras. A onça, pousando no galho da arvore, olhava admirada para nós e muito principalmente para os reflexos da lente do apparelho cinematographico - provavelmente uma novidade para ela.

Dado o primeiro tiro, o felino ferido escapuliu mato adentro, e com um clima de expectativa o relato coloca-nos na posição de Reis, desarmados de armas mais poderosas, os zagaieiros foram chamados por gritos vindos de 500 metros mais adiante, novamente carregando os equipamentos, chegaram a um ponto seguro, mas novamente o animal escapou ao cerco. Muito perto estava novamente Fortunato acuando-a com sua zagaia e dizendo para Reis: "Pode vir, tenente, o gato esta seguro".

Reis preparou a câmara, mas a onça reagiu saltando para o mato alto, nesse momento um clima ainda maior de expectativa, pois agora já não se viam todos, somente gritos, e continua Reis uma narrativa muito tensa na qual relata a presença do felino muito próximo a eles, a poucos metros da câmara:

Neste momento dous cães, salvadores alcançavam o animal e este, para defender-se dos cães acuou em atitude de os atrahir a uma cilada... foi neste momento que, sem serem

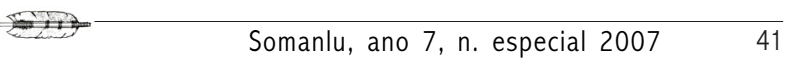


Caçada de onças. Um relato etnográfico de um filme...

presentidos, os zagaieiros alcançaram-na e enterraram-lhe os ferros no dorso indefeso, ao tempo em que eu disparava o revolver, apontado para um dos olhos da onça já extenuada, matando-a immediatamente. Como da outra vez, tudo correu com rara felicidade para nós, mas ainda os films não satisfaziam; e comprehende-se porque a onça não luctava, fugia e acuava em sitios onde nem se podia enxergal-a nitidamente.

Novamente frustrado pela não realização das filmagens, uma discussão percorreu os mateiros, pois o rastro da fêmea de grande porte não condizia com o pequeno animal abatido, e voltaram no dia seguinte para a mesma região. Reis estava incansável à procura de tomadas para seu filme, uma clara obsessão por realizar um filme inédito, que não lhe foi possível na Expedição Roosevelt/Rondon. Como se a região fosse permeada de felinos, os cachorros logo encontraram outro animal, agora em lugar mais fácil de entrar com os equipamentos e, confirmando as leituras indiciais, a onça era uma fêmea e muito feroz. Entretanto, o lugar onde ela estava era muito assobradado e com pouca luz:

A profunda escuridão não aconselhava trabalhar no instantaneo de menor velocidade; era quasi impossivel poder imprimir film com tal fraqueza de luz. O ambiente era como um tunnel, a arvore - como um grande chapéo de sol impenetravel á luz - unia os seus ramos mais baixos aos das arvores visinhas. Por descargo de consciencia aparafusei o aparelho e esperei. O Nery alvejava a onça no queixo inferior; a bala partindo ferira-a na sua principal defesa. $\mathrm{O}$ tigre, tendo sido attingindo na bocca, balançara a cabeça algumas vezes, depois pulando de uma arvore para outra mais baixa, cahiu ao solo para acuar no fundo de um entrançado de cipós e acurys, deixando a pequena clareira onde estavamos. Os cães o atacaram naquelle refugio emquanto eu mudava de estação dirigindo o apparelho para o ponto interessante. Um dos camaradas para mostrar coragem investiu contra a onça á zagaia, tendo infelizmente dado um passo e cahido em posição horizontal, a poucos passos da fera. Esta avançou incontinente sobre a nova presa e tel-a-ia estraçalhado se não fosse a agilidade do Cornelio que acudiu, ferindo a onça com um profundo

\footnotetext{
42 Somanlu, ano 7, n. especial 2007
} 
golpe de zagaia, abaixo do pescoço. $\mathrm{O}$ apparelho funccionava lentamente para registrar o assumpto e dou graças em poder ainda contar com estes poucos metros de film, apanhados calmamente na escuridão da mata!

Mais ainda decepcionado depois dessa terceira tentativa, Reis concluiu sua experiência para filmar a caçada de onça, indica que talvez não tenha realmente editado tais filmagens, pois diz que as dificuldades de filmagem, a luz, a vegetação, a mudança constante de posição, a cor do animal que se mistura com os tons de cinza da mata, e o próprio medo do felino que acuado não ataca, faz o relatório de filmagem mais atraente do que as filmagens, deixando-o frustrado depois de tantas tentativas. Infelizmente, o filme até agora não foi encontrado, mas o relato de Reis descreve os eventos com detalhes e cria uma dramaticidade que pretendia explorar na narrativa cinematográfica, sem ajuda da agressividade e ferocidade dos felinos, como ele mesmo escreve. Provavelmente ainda teremos surpresas, pois cenas dessas caçadas fazem parte do programa cinematográfico "Wildness" apresentado em Nova Iorque, no Carnagie Hall, em 1919, quando Reis lá esteve a convite de Theodor Rooselvelt. $^{2}$

Retornando para Corumbá depois das tentativas de filmagens da caçada, Reis manda imprimir programas e bilhetes, faz acordo com um empresário local de $60 \%$ da bilheteria na primeira exibição e $50 \%$ na segunda, tendo ele de pagar a música, e passa o filme Matto-Grosso em Revista que estava em gestão no primeiro relatório, e que podemos concluir que foi editado nessa estadia. Esse filme também geralmente não consta de sua filmografia e não é encontrado, talvez por ter sido deixado em Cuiabá, e por lá ter se perdido ou estar guardado em algum baú, mas mesmo assim ainda indica que a película poderia render mais bilheteria além dessas apresentações: "Apurei assim a renda de $957 \$ 600$ conforme a nota de receita que vae anexa. Em Cuiabá deixei este film aos cuidados do nosso companheiro Germano Silva que enviará a renda dalli’. As notas são sempre um indicativo que todas suas ações eram acompanhadas e aceitas por seus chefes imediatos, o que de certa forma também legitimava as ações da Comissão Rondon e do SPI nos locais em que tinham sua base mais forte, principalmente Cuiabá, onde era sediado o escritório central da Comissão. 


\section{Notas}

${ }^{1}$ Manteve-se a ortografia original. (N. do Ed.)

${ }^{2}$ Nesse sentido, ver meu artigo recentemente publicado, “A amplitude cinematográfica de Luiz Thomaz Reis", Cadernos de Antropologia e Imagem, n. 20, NAI/UERJ, 2005. p. $97-110$.

\section{Referência}

GUSMÃO, Clovis de (1942). Rondon. Rio de Janeiro: Livraria José Olympio. JORDAN, Pierre(1992). Premier contact-premier regard. Marseille: Musée de Marseille/ Images en Manluvres Editions.

LASMAR, Denise Portugal (2002). Estoques de informação: o acervo imagético da Comissão Rondon no Museu do Índio como fonte de informação. Dissertação de Mestrado (Programa de Pós-Graduação em Ciência da Informação). Escola de Comunicação da UFRJ, Rio de Janeiro.

MAGALHÃES, Amílcar Botelho de (1930). Pelos sertões do Brasil. Rio de Janeiro: Livraria do Globo.

(1942). Impressões da Comissão Rondon. 5 ed., illustrada, actualizada e augmentada. Rio de Janeiro: Companhia Editora Nacional.

(1943). O problema de civilização dos índios no Brasil. América Indígena. México, v. III, n. 2, abril.

PIAULT, Marc Henri (2001). O corpo nu dos índios e o soldado redentor: da indianidade e da brasilidade. Cadernos de Antropologia e Imagem. v. 12, n. 1, p. 87-117. MONTE-MÓR, Patrícia (2004). Tendências do documentário etnográfico. In TEIXEIRA, Francisco Elinaldo (Org.). Documentário no Brasil. São Paulo: Summus. REIS, Luiz Thomaz (1918). Relatório apresentado ao Capitão Amilcar Armando Botelho de Magalhães, chefe do Escritório Central da CLTEMGA, pelo $2^{\circ}$. Tenente Luiz Thomaz Reis, encarregado da Secção de Photographia e Cinematographia, de outubro de 1916 a março de 1917. Supplemento n.07 - Relatório do Sr. $2^{\circ}$. Tenente Luiz Thomaz Reis encarregado da Secção de Photographia e Cinematographia (Documento microfilmado MI SARQ Microfilme 328 fotogramas 1090 a 1131). In Commissão de Linhas Telegraphicas Estratégicas de Matto-Grosso ao Amazonas, relatório dos trabalhos executados durante o anno de 1916 pelo Escriptório Central, no Rio de Janeiro. Apresentado ao Sr. Coronel Cândido Mariano da Silva Rondon,

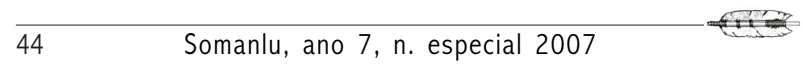


Fernando de Tacca

chefe da Comissão, pelo Capitão de Engenharia Amilcar Armando Botelho de Magalhães, chefe do mesmo escriptorio, em fevereiro de 1918. (Documento microfilmado MI SARQ microfilme 328, fotogramas 685 a 1146.).

(1919). Memorandum de Thomaz Reis ao General Cândido Mariano da Silva Rondon. Rio de Janeiro, setembro de 1919. (Documento microfilmado MI SARQ Microfilme 329, fotogramas 1500 a 1512.).

RIBEIRO, Darcy (1958). O indigenista Rondon. Rio de Janeiro: Ministério da Educação e Cultura - Serviço de Documentação.

RONDON, Cândido Mariano da Silva (1916). Missão Rondon-Apontamentos realizados pela Commissão de Linhas Telegraphicas Estratégicas de Matto-Grosso ao Amazonas de 1907 a 1915. Rio de Janeiro: Typ.do Jornal do Commercio.

(1920). Relatório dos trabalhos realizados de 1900-1906. Commissão de Linhas Telegraphicas Estratégicas de Matto-Grosso ao Amazonas. Rio de Janeiro: Departamento de Imprensa Nacional.

(1922). Conferencias - Realizadas em 1910 no Rio de Janeiro e em S.Paulo.

Commissão de Linhas Telegraphicas Estratégicas de Matto-Grosso ao Amazonas. Rio de Janeiro: Typographia Leuzinger, n. 68.

(1945). Expedição ao Rio Ronuro (1924). Rio de Janeiro: Ministério da Agricultura; CNPI; Imprensa Nacional.(Relatório do Cap. Vicente de Paulo Teixeira da Fonseca Vasconcelos, anexos dois relatórios do Capitão Luiz Thomaz Reis sobre: 1. Serviços Fotográficos e Cinematográficos e 2. Serviço Antropométrico).

(1953). Índios do Brasil-Cabeceiras do Xingu/Rio Araguaia e Oiapóque. Rio de Janeiro: Ministério da Agricultura; CNPI, v. II, n. 98.

(1956). Índios do Brasil - Norte do Rio Amazonas. Rio de Janeiro: Ministério da Agricultura; CNPI, v. III, n. 99.

ROOSEVELT, Theodore (1942). Nas selvas do Brasil. 2 ed. Rio de Janeiro: Ministério da Agricultura.(Edição original publicada em 1914).

TACCA, Fernando de (1996). A imagética da Comissão Rondon. Osaka University of Foreign Studies Review, Spring, New Series 16.

(1998). O índio pacificado: uma construção imagética da Comissão Rondon. Cadernos de Antropologia e Imagem, n.06, p.

(1996). A imagética da Comissão Rondon - Etnografias fílmicas estratégicas.

Campinas: Papirus.

(2002). Rituais e Festas Bororo.A construção da imagem do índio como

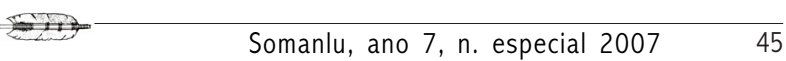


“selvagem" na Comissão Rondon. Revista de Antropologia, v. 45, n.1, p. 187-219. (2004). Luiz Thomaz Reis: etnografias filmicas estratégicas. In TEIXEIRA, Francisco Elinaldo(Org.). Documentário no Brasil. São Paulo: Summus, p. 313-370. (2005). A amplitude cinematográfica de Luiz Thomaz Reis. Cadernos de Antropologia e Imagem, n.20, p. $97-110$.

VIVEIROS, Esther de (1958). Rondon conta sua vida. Rio de Janeiro: Livraria São José. 